\title{
EL LUGAR DE LA LIBERTAD EN LAS SOCIEDADES NIHILISTAS
}

\author{
David Porcel Dieste \\ I.E.S. Marco Fabio Quintiliano (Calahorra, La Rioja)
}

RESUMEN: El nihilismo es considerado por algunos filósofos contemporáneos como el problema fundamental del siglo XX. Pensadores como Ortega y Gasset, Heidegger o Ernst Jünger ensayan diferentes propuestas filosóficas para definir la naturaleza del nihilismo contemporáneo y orientar al ser humano en las sociedades nihilistas. En este artículo se descubren algunas claves para comprender la naturaleza del problema y la responsabilidad del hombre singular en la superación de las formas nihilistas de poder. No se equivoca Heidegger cuando afirma que el aspecto inquietante del mundo contemporáneo no es tanto que éste se convierta en un mundo completamente técnico, regido exclusivamente por la razón instrumental, como que el hombre no esté preparado para esta transformación del mundo.

Palabras clave: Nihilismo, sociedades contemporáneas, formas nihilistas de poder, responsabilidad, superación.

ABSTRACT: Nihilism is considered by some present-day philosophers as the underlying problem of the twentieth century. Thinkers as Ortega y Gasset, Heidegger or Ernst Jünger test different philosophical proposals to define the essence of contemporany nihilism and to guide human being in nihilist societies. This article finds out some clues to understand the nature of the problem and the singular man s responsibility in order to overcome the nihilistic power. Heidegger wasn t wrong when he said that the disturbing aspect of contemporary world is not that it becomes quite technical, governed solely by instrumental reason, but that man is not prepared for this changing world.

Keywords: Nihilism, contemporany societies, nihilistic power, responsability, overcoming. 


\section{Hacia una definición del «problema del nihilismo»}

Filósofos y escritores influyentes del siglo pasado como Martin Heidegger, Ernst Jünger y Ortega y Gasset no han dudado en considerar el «nihilismo» como el problema fundamental de las sociedades contemporáneas. Estos pensadores coinciden en considerar el nihilismo como el mal constitutivo de un siglo marcado por la crisis de los valores tradicionales procedentes del cristianismo, la llustración y el racionalismo positivista. El optimismo que reina en el ambiente de comienzos del siglo XX en Occidente se ve pronto truncado por el advenimiento de los fascismos y totalitarismos, el caso Dreyfus o desastres como el hundimiento del Titanic, símbolo del dominio técnico sobre la Naturaleza. En la esfera política los desastres de las guerras mundiales cuestionan la concepción positivista de la historia que ve en ésta un camino seguro hacia el conocimiento y la felicidad. En el ámbito científico, numerosos descubrimientos rompen la concepción positivista y mecanicista del mundo que había supuesto la íntima conexión entre las leyes que rigen el mundo y los principios formales que determinan el pensamiento ${ }^{1}$. Por otro lado, el hombre comienza a cuestionarse si el progreso científico y tecnológico, que tanto incrementa la calidad de vida, contribuye verdaderamente al desarrollo espiritual del ser humano. Como señala Franco Volpi en su estudio sobre el nihilismo contemporáneo: "nadie pone en duda que el crecimiento del imperio tecnológico presenta una infinidad de aspectos positivos y fascinantes, y abre una infinidad de nuevas potencialidades. Al mismo tiempo, es difícil acallar las inquietudes y las preocupaciones en torno a la amenazante eventualidad de que, en vez de promover la realización del hombre, la tecno-ciencia termine por erradicarlo de su mundo natural y cultural, empobreciendo sus recursos simbólicos"2 ${ }^{\prime 2}$.

El otro aspecto común que comparten estos filósofos contemporáneos es la asunción de la crítica a toda forma de metafísica donadora de sentido que un siglo atrás había esbozado Nietzsche, considerado por muchos como el primer gran profeta y teórico del nihilismo. En su estudio sobre el nihilismo, Volpi sintetiza la esencia del nihilismo como la falta absoluta de sentido, unidad y verdad, afirmando que "el nihilismo es, por lo tanto, la «falta de sentido» que aparece cuando se debilita la fuerza vinculante de las respuestas tradicionales al « ¿para qué?» de la vida y del ser, y esto sucede a lo largo del proceso histórico

1. Uno de los descubrimientos científicos que rompe con la concepción racionalista del conocimiento humano es el que Ilevan a cabo los físicos Max Plank y Albert Einstein sobre la naturaleza de la luz a comienzos del pasado siglo. Sus conclusiones parecen contradecir el principio lógico de la no contradicción: la luz tiene una doble naturaleza, es onda y corpúsculo a la vez. En efecto, se trata de una onda continua expandida por el espacio, pero también consiste en un conjunto de partículas Ilamadas fotones; véase, , Antonio Fernández-Rañada, Los científicos y Dios, pp. 99-102.

2. Volpi, Franco, El nihilismo, Madrid, Siruela, 2007, pp. 164-165. 
en el curso del cual los supremos valores tradicionales que daban respuesta a aquel "¿para qué?»-Dios, la Verdad, el Bien- pierden su valor y perecen"3. Así, la idea de «nihilismo» significa que el devenir no tiende a ninguna meta, no apunta a nada; no subyace, por tanto, ningún sentido en todo cuanto sucede y, consecuentemente, no hay ninguna verdad que descubrir tras los fenómenos. La consecuencia lógica del nihilismo es la sensación de desorientación que sobreviene cuando fallan los ideales y valores que iluminan la acción del hombre. Nietzsche ya augura que tras la crisis de los valores trascendentales y de la idea misma de valor, lo que queda es la sospecha de que no hay ningún referente ético que dicte cuál es el camino a seguir: "El hombre moderno cree de manera experimental ya en este valor, ya en aquél, para después dejarlo caer; el círculo de los valores superados y abandonados es cada vez más amplio; se advierte siempre más el vacío y la pobreza de valores; el movimiento es imparable, por más que haya habido intentos grandiosos por desacelerarlo. Al final, el hombre se atreve a una crítica de los valores en general; no reconoce su origen; conoce bastante como para no creer más en ningún valor; he aquí el pathos, el nuevo escalofrío... La que cuento es la historia de los dos próximos siglos..." ${ }^{4}$.

En este contexto cultural, marcado por el fracaso anunciado del programa positivista de alcanzar una sociedad buena y segura y por el vacío de referentes éticos que antaño iluminaban la acción del hombre, prosperan las filosofías que buscan orientar al ser humano hacia nuevos horizontes vitales. El problema de fondo que preocupa a filósofos como Jünger u Ortega consiste en cómo preparar al individuo para la llegada inevitable del nihilismo: "El hombre libre está ya obligado por motivos de autoconservación a preocuparse por cómo comportarse en un mundo en el que el nihilismo no sólo se ha vuelto dominante, sino, lo que todavía es peor, también se ha convertido en un estado normal"5.

\section{El nihilismo como la raíz de la que se nutren las formas coercitivas de poder}

Ernst Jünger, continuando el camino que un siglo atrás había comenzado su maestro Nietzsche, reconoce la nueva máscara en la que se oculta el nihilismo en el imperialismo de los totalitarismos políticos y del automatismo tecnológico. El auge de estas formas de poder y el valor absoluto que las ideologías totalitarias otorgan a una idea o programa políticos, hacen sospechar a Jünger que todavía no se ha alcanzado ese nihilismo completo que Nietzsche anunciaba para los dos próximos siglos: "La forma extrema del nihilismo sería sostener que toda fe, todo tener por verdadero es necesariamente falso: porque no existe en

3. Volpi, Franco, El nihilismo, p. 61.

4. Nietzsche, Friedrich, Sämtliche Werke. Kritische Studienausgabe, Múnich, dtv, Berlín, 1988, vol. XIII, pp. 56-57 en Volpi, Franco, El nihilismo, p. 14.

5. Jünger, Ernst, Sobre la línea, Barcelona, Paidós, 1994, p. 49. 
absoluto un MUNDO VERDADERO. Por lo tanto: una perspectiva ilusoria, cuyo origen está en nosotros (teniendo nosotros constantemente necesidad de un mundo limitado, abreviado, simplificado) ${ }^{\prime \prime}$. Una de las conclusiones a las que llega el filósofo alemán en sus estudios sobre los totalitarismos políticos es que el nihilismo y el poder son inseparables. Por un lado, el poder tiránico se sirve para acrecentar su poder del rumor nihilista, por el que los ciudadanos Ilegan a convencerse de que ya no hay valores ni fuerza interior con los que oponer resistencia; por otro lado, el pensamiento nihilista alimenta el desarrollo de nuevas formas coercitivas de poder, que buscan reducir la libertad y someter al ser humano a una legalidad impuesta.

En su ensayo Sobre la línea (1951) Jünger analiza las relaciones íntimas entre el poder autoritario y el pensamiento nihilista, advirtiendo que las formas coercitivas e impositivas propias del poder totalitario y tecnocrático tienen su origen en el nihilismo. En efecto, el vacío de referentes éticos propio de las sociedades nihilistas conduce a la legitimación de prácticas coercitivas de poder, que ya no encuentran ningún tipo de resistencia en la ética ni en la religión y se propagan tanto en la vida social como en la vida íntima. Al mismo tiempo, ese vacío interior, que se traduce en la pérdida de referentes éticos, provoca en quien lo siente la necesidad de sujetarse a cualquier norma sin tener en cuenta su procedencia o pretensión: "Dos grandes miedos dominan a los hombres cuando el nihilismo culmina. El uno consiste en el espanto ante el vacío interior, y le obliga a manifestarse hacia afuera a cualquier precio por medio de despliegue de poder, dominio espacial o velocidad acelerada. El otro opera de fuera hacia dentro como ataque del poderoso mundo a la vez demoníaco y automatizado. En ese doble juego consiste la invencibilidad de Leviatán en nuestra época" ${ }^{\prime \prime}$.

Por tanto, a juicio de Jünger, el poder de los Estados totalitarios y tecnocráticos se funda en el nihilismo, en ese espanto ante el vacío interior que experimenta tanto el que ostenta el poder como el que lo padece. Ello explica que allí donde se ve caer una de las múltiples formas como se manifiesta el Estado totalitario, en las sociedades nihilistas resurgen nuevos poderes despóticos. El vacío de valores y de fe lo exige y obliga al ser humano a sujetarse a cualquier forma autoritaria de dominio, ya sea técnica o política. El individuo, desprovisto de valores y de metas, necesita de una autoridad que le dicte lo que tiene que hacer; en definitiva, necesita de otro que le exima de la responsabilidad de labrar su destino personal: "Si se consiguiera derribar a Leviatán -afirma Jünger-, tendría que se rellenado el espacio así liberado. Pero el vacío interior, el estado $\sin \mathrm{fe}$, es incapaz de semejante postura. Por ese motivo, allí donde

6. Nietzsche, Friedrich, El nihilismo: escritos póstumos, Barcelona, Península, 1968, p. 67.

7. Jünger, Ernst, Sobre la línea, p. 57. 
vemos caer una copia del Leviatán, crecen nuevas imágenes a cabezas de la Hidra. El vacío las exige"

Así, para Jünger las formas de poder a las que debe oponer resistencia el individuo se alimentan del nihilismo. Estas formas de poder son los totalitarismos políticos y el imperio de la tecno-ciencia. El autor entiende que la falta de valores y de fe se traduce tanto en formas políticas de dominación como en sociedades tecnocráticas regidas por la absolutización del valor de la eficiencia y de la rentabilidad. A continuación analizaremos el modo como ejercen su dominio sobre el hombre concreto dichas formas de poder y el fin último que éstas persiguen. La comprensión de los mecanismos del poder, como veremos, constituye el primer paso para su superación.

\section{El imperialismo de la Razón y la educación al servicio del poder}

A comienzos del siglo pasado, Jünger interpreta el programa científico y político de la llustración como el comienzo de una de las formas políticas de poder contemporáneas. Ésta se basa en la presunción de que es posible reducir todo cuanto existe a lo racional. El imperialismo de la Razón consiste precisamente en la tendencia a racionalizar lo real, de forma que no quede nada fuera del dominio de aquélla. En su obra El trabajador (1932) Jünger analiza esta forma de poder que ejercen los burgueses -herederos del espíritu ilustrado y democrático del siglo XIX-sobre los trabajadores alemanes. Los primeros no solo creen que el progreso científico y tecnológico es posible, sino que es una condición necesaria para el desarrollo de la humanidad; mientras, los trabajadores, que han sido educados en el dolor y el peligro durante los combates en la primera guerra mundial, conciben la razón como una capacidad supeditada a la pasión: "El único heredero posible del prusianismo, el trabajador no excluye, empero, lo elemental, sino que lo incluye; él ha pasado por la escuela de la anarquía, por la destrucción de los vínculos antiguos, y de ahí que tenga que efectuar su reivindicación de libertad en un tiempo nuevo, en un espacio nuevo y mediante una aristocracia nueva" ${ }^{\prime \prime}$.

En obras como La movilización total (1931), El trabajador (1932) y Sobre el dolor (1934) Jünger inicia la crítica feroz hacia la política de dominación que a su entender ejerce el hombre burgués, heredero del espíritu ilustrado decimonónico, sobre los trabajadores, educados en el fragor del combate y la dura disciplina a la que se habían visto sometidos durante la primera gran contienda europea. El valor absoluto que el burgués atribuye a la razón, así como el afán exclusivo de seguridad que gobierna su vida, hacen suponer a Jünger que todavía las sociedades occidentales se hallan presas de ideologías totalitarias. Como

8. Jünger, Ernst, Sobre la línea, pp. 57-58.

9. Jünger, Ernst, El trabajador, Barcelona, Tusquets, 1993, p. 71. 
afirma Alain de Benoist en su Comunismo y nazismo: "Las democracias liberales defienden, es cierto, los derechos humanos, pero esta postura es en sí misma equívoca. (...) Al igual que los totalitarismos de ayer, tampoco están dispuestos a aceptar que sus normas no sean necesariamente asumidas y reconocidas. También ellas tienden a imponerse como el único sistema universalmente posible, en nombre de una ideología que, por «humanista» que sea, da paso a todos los abusos en la medida en que es presentada como una «evidencia» que se supone tiene que imponerse a todos"10. Jünger, en este sentido, también entiende que las sociedades liberales continúan legitimando la dominación del mundo, solo que con métodos distintos, como las leyes del mercado, la técnica y la comunicación. En definitiva, dichas sociedades usan métodos no violentos para pretender los mismos fines que los totalitarismos: reducción de la diversidad de costumbres y opinión a lo mismo, tendencia a la uniformización y al pensamiento único, estandarización de los gustos, sentimientos y costumbres, moldeamiento de los comportamientos sociales a pautas impuestas e interesadas...

En esta situación Jünger escribe El trabajador, donde asienta las bases para acabar con este imperialismo de la Razón y reclamar otros derechos si cabe más fundamentales que el de la libertad y la seguridad. Para ello primero el autor trata de desenmascarar las argucias de poder que emplean los burgueses y demócratas para someter a sus principios cívicos a los trabajadores alemanes. El trabajador representa para el burgués justamente aquello que éste repudia y teme: un espíritu dionisíaco, pasional, guerrero, capaz de sobreponerse al dolor y al miedo. Recordemos que el proyecto procedente de la Ilustración, que hereda el ciudadano burgués a comienzos del siglo pasado, tiene como meta última alcanzar una sociedad buena, segura y razonable. En dicho proyecto no tienen cabida aquellos elementos y tendencias que no se ajustan a la lógica racional o amenazan ese espacio exclusivo de seguridad. Este proyecto, desde el punto de vista de la mentalidad ilustrada, solo es alcanzable racionalizado la Naturaleza, es decir, categorizándola conforme a los principios formales de la razón y otorgándole el privilegio de ajustarse a las leyes y normas racionales. Así, la estrategia que emprende el burgués de racionalizar todo cuanto existe conduce a tachar de irracionales aquellas conductas que amenazan su seguridad y bienestar, y a legitimar la condena y censura de dichas actitudes. En definitiva, lo que pretende el burgués es relegar su objeto de amenaza al reino del no ser, al ámbito de lo que no debe ser. El triunfo se basa en este hecho, y el mejor medio del que dispone el burgués es de una pedagogía que anule el modo de pensar, sentir y actuar propio del trabajador: "La situación ideal de seguridad que el progreso aspira a alcanzar consiste, por el contrario, en que el mundo sea dominado por la razón, la cual deberá no sólo aminorar las fuentes de lo peligroso, sino también, en última instancia, secarlas. El acto en que eso ocurre es precisamen-

10. De Benoist, Alain, Comunismo y nazismo, Barcelona, Áltera, 2005, pp. 153-154. 
te aquel en que, a la luz de la razón, lo peligroso de revela como lo absurdo y pierde así, por tanto, su derecho a ser real"11.

Sin embargo, Jünger advierte a comienzos del siglo pasado que hasta ese momento no han cuajado los valores de la Ilustración en la mentalidad de los trabajadores alemanes. Ello se debe al desajuste que existe entre la concepción ilustrada de la libertad y la responsabilidad y el modo específico de ser de aquéllos: "En todas partes cabe ofrecer pruebas detalladas de tal discordia; su razón se encuentra en que los alemanes no supieron hacer uso ninguno de esa libertad que se les ofrecía con todas las artes de la espada y de la persuasión, no supieron hacer uso de la libertad que había quedado instaurada con la proclamación de los derechos universales del hombre: y es que para los alemanes era esa libertad un instrumento que no guardaba la menor relación con sus órganos más íntimos y propios $^{\prime 12}$. En efecto, asegura Jünger, el burgués, heredero directo del hombre ilustrado y racionalista, ha tratado de someter a su dominio al trabajador, viendo en éste la representación del cuarto estado, de una sociedad o de una economía nuevas, es decir, relegándolo al espacio de la negociación y del contrato, y pretendiendo que asimilara y asintiera los valores y principios de la Ilustración. Lo que ignora burgués, advierte el autor, es la imposibilidad ontológica de que el trabajador acabe asimilando a su manera de pensar, de sentir y de querer aquellos valores. Por ello Jünger reivindica una nueva actitud en los trabajadores por las que éstos dejen de verse como pretende vanamente el burgués y comiencen a comportarse conforme a su idiosincrasia: "Si es que queremos atrevernos a emprender una ofensiva nueva, no podemos hacerlo sino en dirección a unos objetivos nuevos. Esto tiene como presupuesto un frente diferente y unos aliados diferentes. Esto tiene como presupuesto que el trabajador se conciba a sí mismo de una manera diferente y que en sus movimientos cese de expresarse un reflejo de la conciencia burguesa y comience a expresarse una conciencia peculiar de sí mismo"13.

Así, el análisis de Jünger del ejercicio burgués de poder nos descubre que el fin general que buscan las formas políticas de poder consiste en negar el derecho a ser y a manifestarse de todo aquello que en principio pueda constituir un objeto de amenaza para aquéllas. Este fin, al que deberá hacer frente el individuo, se reproduce en la otra forma de poder contemporáneo: el imperialismo de la tecno-ciencia.

\section{El imperialismo del automatismo tecnológico en las sociedades contemporáneas}

Durante el siglo XIX y comienzos del XX la ciencia y la tecnología son consideradas como saberes favorables al progreso humano. La filosofía positivista de

11. Jünger, Ernst, El trabajador, p. 54.

12. Jünger, Ernst, El trabajador, p. 20.

13. Jünger, Ernst, El trabajador, p. 37. 
Auguste Comte sitúa a las ciencias positivas en la cima del conocimiento y del progreso humanos ${ }^{14}$. Por otro lado, la ciencia y la técnica, en cuanto desarrollos de la razón, se consideran actividades humanizadoras. Sin embargo, a comienzos del siglo pasado se despiertan dudas respecto a la identificación entre el progreso científico-tecnológico y la realización cultural y espiritual del hombre. La tecnología, si bien amplía nuestras posibilidades existenciales, reduce la apertura a nuestros lazos naturales y espirituales. Por otro lado, como señala Franco Volpi, en las sociedades tecnológicas existe el problema de que no disponemos de un referente antropológico y ético que permita valorar y decidir qué hacer ante la infinitud de posibilidades a la que nos abre la técnica. El peligro consiste en vivir mirando únicamente lo que se puede hacer y desatendiendo lo que se debe hacer, en construir un mundo al margen de nosotros, un mundo en el que el sujeto de la historia sea la técnica, y no ya el ser humano. Un mundo así estaría regido únicamente por la voluntad de poder y de ampliación de posibilidades a través de la explotación de la técnica: "Así, las transformaciones que se han producido han acelerado el desencanto y la crisis de fundamentos, es decir, la erosión y la disolución de los marcos de referencia tradicionales. Se ha abierto así una fractura cada vez más profunda entre el homo faber y el homo sapiens, entre aquello que el hombre sabe y puede hacer, por un lado, y su capacidad de valorar y elegir aquello que es razonable hacer"15.

Filósofos como Jünger y Ortega ${ }^{16}$ no son insensibles a esta transformación de las sociedades contemporáneas y ven en la tecnología un poder capaz de subordinar a su disciplina hasta el último de los átomos. Los nuevos Estados tecnocráticos encarnan nuevas formas nihilistas de poder que buscan arrancar al ser humano su libertad singular. La nueva fuerza coercitiva ahora no va a ser la educación, sino la técnica al servicio de los poderes políticos y económicos. Como señala Franco Volpi, la ciencia y la técnica actuales, que acortan el espacio y aceleran el tiempo, que alivian el dolor y alargan la vida, "imponen obligaciones que vinculan más que todas las éticas escritas en la historia de la humanidad, volviendo superfluo, de ahora en adelante, todo otro imperativo" ${ }^{17}$. En efecto, la ciencia y la técnica organizan la vida hasta el punto que hoy día parece impensable vivir fuera del espacio gobernado por esos imperativos procedentes de la tecno-ciencia. Por ello, piensa Jünger, no solo en tiempos de opresión política sino también en períodos de paz y prosperidad económica, el

14. Véase Comte, Auguste, Discurso sobre el espíritu positivo, Barcelona, Ediciones Folio, 2002.

15. Volpi, Franco, El nihilismo, p. 165.

16. La concepción optimista que tiene el filósofo español de la técnica no es incompatible, como veremos, con algunos problemas que a su entender se derivan del creciente progreso tecnológico y de las sociedades tecnificadas.

17. Volpi, Franco, El nihilismo, p. 190. 
despliegue tecnológico, por su propia naturaleza, tiene el poder de subordinar a sus imperativos y funciones a la persona singular.

\section{El «lado obscuro» de la técnica}

Jünger es de la opinión de que también en tiempos de paz y prosperidad puede observarse el ejercicio técnico de poder basado en los mismos principios que los totalitarismos políticos. En las sociedades actuales, el derecho a la libertad de investigación, al aumento de producción de capital y al incremento de la calidad de vida legitiman el creciente despliegue tecnológico propio de nuestro tiempo. Como señala Volpi, en las sociedades nihilistas contemporáneas, en las que se absolutiza el derecho a la libertad de producción y comercio, la ciencia y la técnica contemporáneas no reconocen otro límite que aquello que es técnica o científicamente posible. Incluso el universal «hombre», que en hace unos siglos fue objeto de especulaciones abstractas y definiciones filosóficas, "se ha transformado hoy en una entidad concreta, disponible en el laboratorio en la forma de genoma y susceptible de ser tratada y modificada"18.

Jünger, atento a la sustitución de la «razón contemplativa» por la «razón instrumental», descubre tras el progreso tecnológico cierto retroceso espiritual que aleja al humano de sus raíces naturales y espirituales. En su novela Abejas de cristal (1957), el autor describe el carácter imperceptible con el que la sociedad contemporánea va adecuando sus comportamientos a los ritmos y tareas que imponen los autómatas. La ciudad donde se desarrolla la acción está plagada de robots liliputienses inventados por el ingeniero Zapparoni, que ha creado un auténtico monopolio de estos aparatos diseñados para todos los fines imaginables. Sus aparatos enseguida se vuelven imprescindibles para la industria, la ciencia y el hogar. Economizan mano de obra, aceleran y perfeccionan los ritmos de la naturaleza y crean, en el ámbito de la técnica, un clima desconocido hasta el momento: "Un cerebro ingenioso había detectado una laguna en la que nadie se había fijado hasta entonces y la había llenado. Así es como se hacen los grandes negocios; los mejores"19. En esta situación se llega incluso a pronosticar que la técnica alcance la hechicería pura por su capacidad de hacer realidad al instante cualquier deseo humano: "Llegado ese momento, todo lo que hacemos ahora no habrá sido sino un impulso inicial y la mecánica se habrá refinado de tal forma que ya no exija nuestra torpe manipulación. Bastarán unas luces, unas palabras, más aún, un mero pensamiento. Un sistema de impulsos inundará y recorrerá el mundo" ${ }^{20}$.

18. Volpi, Franco, El nihilismo, p. 163.

19. Jünger, Ernst, Abejas de cristal, Madrid, Alianza Editorial, 1985, p. 14.

20. Jünger, Ernst, Abejas de cristal, p. 44. 
El optimismo tecnológico que encarna Zapparoni contrasta con la nueva manera de actuar de los habitantes de la ciudad tecnificada. El ambiente tranquilo y sereno en el que vive Zapparoni, en contacto inmediato con la Naturaleza y la sabiduría, contrasta con el mundo automatizado en el que interactúan sus habitantes. En todos los lugares los animales de caballería se sustituyen por autómatas. Y este cambio se produce a la par que una transformación en los hombres: sus movimientos se vuelven cada vez más mecánicos y previsibles, hasta el punto que se tiene la sensación de no vivir entre humanos. Los autómatas de Zapparoni parecen arrebatar incluso a los niños su libertad elemental, que ya no juegan hasta que se pone el Sol o se cansan, sino hasta que sus robots fijan el término de la sesión. En suma, la uniformidad, predictibilidad y mecanización de los comportamientos humanos se traducen en una reducción de la libertad y espontaneidad del individuo, que, hechizado bajo el influjo de los liliputienses, ve mermada su capacidad para atender sus deseos genuinos.

Esta tendencia creciente a la participación del "círculo mágico" de los autómatas no depende exclusivamente de la voluntad: querámoslo o no formamos parte integrante de él, ya sea como obreros en una fábrica, oficinistas en una administración, o peatones en la disciplina del tráfico: “El «trabajo» invade los parajes en los que habita el hombre -incluidos estratos considerados por el burgués como reducto privado e inalienable del individuo- transformándolos en 'paisajes de taller' i.e., espacios (externos o internos) caracterizados por su carencia de valores absolutos, la aplicación de criterios pragmáticos y tecnocráticos de decisión, el funcionamiento automático, incluidos los resortes y engranajes de las conciencias, de los cuerpos y de sus estados o hábitos: sobriedad, evasión embrutecedora, movimiento peatonal maquinal, masificación urbana, ocio consumista, etcétera" ${ }^{21}$. Un ejemplo que manifiesta el carácter necesario e imperceptible con el que la persona singular acaba subordinándose al proceso técnico, señala Jünger, es el hecho de que hoy en día apenas existen movimientos de protesta contra la cantidad de víctimas que a diario se produce por la disciplina del tráfico. Nadie protesta ni se desconcierta por el número de víctimas porque ello forma parte de la orden del día y del modo de vida contemporáneo.

Por tanto, el dominio del mundo tecnificado sobre el individuo se hace visible en el creciente proceso de subordinación de lo humano a la legalidad que impone la técnica y, de manera simultánea, en el alejamiento de los ambientes reservados a la vida interior. En su ensayo El libro del reloj de arena (1954) Jünger recuerda la enorme ganancia que supone para el hombre vivir retirado del mundo civilizado, máxime cuando conforme se incrementa el progreso tecnoló-

21. Ocaña, Enrique, Más allá del nihilismo: meditaciones sobre Ernst Jünger, Murcia, Universidad. Secretariado de Publicaciones, 1993, p. 246. 
gico el hombre va alejándose de su naturaleza interior. La tendencia a la participación del mundo tecnológico y a la subordinación pasiva de sus dictados conlleva a la pérdida progresiva de espacios reservados para un contacto inmediato con nuestra naturaleza más íntima. En concreto, Jünger advierte del retroceso espiritual al que conlleva la expansión de la forma mecánica de cuantificar el tiempo. Los primeros relojes mecánicos, verdaderos símbolos del progreso moderno, que permiten dar las horas y los segundos durante la totalidad del día y de la noche, introducen una infinidad de posibilidades vitales todas ellas regidas por sus manecillas. En efecto, hoy en día el tiempo es algo que se puede comprar o vender, ganar o gastar, sincronizar, acelerar...; en fin, se ha convertido en algo imprescindible para organizar y marcar las pautas de nuestros quehaceres cotidianos. El tiempo mecánico constituye, en este sentido, un valor del que no podemos prescindir en nuestras actividades diarias. Forma ya parte insustituible de nuestra circunstancia y debemos contar con él si queremos participar en la vida contemporánea. Pero el tiempo que nos brindan los relojes mecánicos, el mismo que nos abre la posibilidad de organizar y sincronizar el conjunto de nuestras actividades, también coarta y limita peligrosamente nuestra libertad más primitiva y espiritual. Ese tiempo demoníaco, nos advierte Jünger, consigue subordinar el tiempo de la naturaleza a su tempo mecánico, uniforme y sincrónico. Muestra de ello es el deporte, en el que el ritmo natural del corazón debe adaptarse a las exigencias del tiempo mecanizado y numérico: "Las ruedas que giran sin descanso, las cintas inacabables no sólo fuerzan al corazón a seguir su ritmo. También tienen bajo su hechizo a las células. De ahí que estén aumentando no sólo las dolencias del corazón, sino también las degeneraciones de los tejidos" ${ }^{\prime 22}$. El problema, a juicio de Jünger, radica en que ese proceso de imparable subordinación alcanza incluso aquellos espacios reservados para la vida espiritual y creadora, de ahí que en el mundo actual escasean los ambientes tranquilos, que, como el que refleja Alberto Durero en San Jerónimo en su gabinete (1514), invitan a experimentar el tiempo de manera distinta a como se vive en la disciplina que impone el mundo tecnológico.

\section{La pérdida del «ensimismamiento» en el mundo tecnológico}

El filósofo Ortega y Gasset, al hilo de estas ideas, repara en el riesgo actual de que la técnica pueda llegar a obnubilar nuestra conciencia de seres técnicos y creadores. Para el filósofo español, el mundo tecnológico que rodea al hombre contemporáneo se ha convertido en una segunda naturaleza artificial que reemplaza a la auténtica naturaleza en su función de proveer al ser humano de todo aquello que necesita, produciendo la sensación de que la técnica, lo mismo que la naturaleza, está ya ahí dada, regalada: "Y esto tiene un riesgo entre

22. Jünger, Ernst, El libro del reloj de arena, Barcelona, Tusquets, 1998, p. 254. 
otros: como al abrir los ojos a la existencia se encuentra el hombre rodeado de una cantidad fabulosa de objetos y procedimientos creados por la técnica que forman un primer paisaje artificial tan tupido que oculta la naturaleza primaria tras él, tenderá a creer que, como ésta, todo aquello está ahí por sí mismo: que el automóvil y la aspirina no son cosas que hay que fabricar, sino cosas, como la piedra o la planta, que son dadas al hombre sin previo esfuerzo de éste" ${ }^{\prime 23}$.

En su estudio Ensimismamiento y alteración (1939), en relación con estas ideas, Ortega observa que el rasgo idiosincrásico del hombre contemporáneo, inmerso en esta segunda naturaleza, es que vive continuamente fuera de sí mismo, «alterado», atento únicamente a las demandas y llamadas procedentes de su mundo circundante, sin atender por tanto a sus verdaderos deseos. Lo contrario de la alteración es el «ensimismamiento», que Ortega define como la capacidad de recluirse el ser consigo mismo con el fin de iniciar un diálogo interior destinado a resolver alguna urgencia o deseo vitales ${ }^{24}$. Así, para el filósofo español, el hombre actual vive en todo momento alerta, atento a lo que le puedan deparar las posibilidades tecnológicas que se extienden a su alrededor, y entonces, sin pretenderlo, renuncia a toda forma de recogimiento interior que le pueda acercar al conocimiento de su ser: "Casi todo el mundo está alterado, y en la alteración el hombre pierde su atributo más esencial: la posibilidad de meditar, de recogerse dentro de sí mismo para ponerse consigo mismo de acuerdo y precisarse qué es lo que cree y qué es lo que no cree; lo que de verdad estima y lo que de verdad detesta. La alteración le obnubila, le ciega, le obliga a actuar mecánicamente en un frenético sonambulismo" ${ }^{25}$.

Teniendo presente estas ideas, puede pensarse con Ortega que la tendencia en las sociedades tecnológicas actuales consiste en reducir cualquier forma de reclusión interior. En efecto, si todo cuanto deseamos puede ser satisfecho al instante, si, por tanto, no necesitamos idear planes de acción para conseguir esto o aquello, ¿qué sentido tiene ya la capacidad específicamente humana de la ensimismación? La infinidad de artefactos que Ilenan nuestras vidas, lejos de demandar o incitarnos al «ensimismamiento», lo adormecen, lo vuelven cada

23. Ortega y Gasset, Meditación de la técnica, Madrid, Taurus, 2006, Tomo V, p. 598.

24. Ortega no identifica esta capacidad con el repliegue egocéntrico, o muestra de desinterés por el mundo o la sociedad, sino más bien al contrario, como una condición para ponerse el hombre en claro sobre sí mismo, sobre lo que piensa y desea, y, consecuentemente, para abrirse a la posibilidad de construir un programa vital con el mundo y el otro. En suma, el filósofo se refiere a la capacidad de ensimismarse como aquella que permite al hombre, "de cuando en cuando, suspender su ocupación directa con las cosas, desasirse de su derredor, desentenderse de él, y sometiendo su facultad de atender a una torsión radical -incomprensible zoológicamente-, volverse, por decirlo así, de espaldas al mundo y meterse dentro de sí, atender a su propia intimidad o, lo que es igual, ocuparse de sí mismo y no de lo otro, de las cosas." en Ortega y Gasset, Ensimismamiento y alteración, Madrid, Taurus, 2006, Tomo V, p. 535.

25. Ortega y Gasset, Ensimismamiento y alteración, p. 534. 
vez más prescindible, favoreciendo el fenómeno contrario de la «alteración». Así, las sociedades basadas en el consumo y el bienestar se benefician de este tipo de hombre que vive afanándose únicamente en cumplir con lo que dichas sociedades demandan de él. El modo de vida «alterado» beneficia al Estado tecnocrático, que ve incrementado su poder al tiempo que va alejando al hombre de su verdadero ser.

En suma, la consecuencia más grave del progreso tecnológico que observan Jünger y Ortega consiste en la progresiva deshumanización por la que el humano deja de atender las demandas procedentes de su corazón y de su pensamiento para someterse a los imperativos de la tecno-ciencia. Así, el fin último que persigue el imperialismo de la tecno-ciencia coincide con el propósito fundamental que animan las formas nihilistas de poder: anular toda forma de existencia posible que no contribuya a acrecentar su poder. En efecto, tanto los sistemas totalitarios como los Estados tecnocráticos, como hemos visto, pretenden en último término imponer al individuo determinados patrones de comportamiento, de forma que éste no encuentre otra opción vital que la de seguir dichas pautas.

\section{El fracaso anunciado de las formas nihilistas de poder}

Hemos visto que los poderes coercitivos políticos y técnicos pretenden anular la posibilidad misma de cualquier forma de resistencia o modo de vida que reduzcan su poder. Esta pretensión, sin embargo, resulta vana si se considera que el poder de las fuerzas opresoras es, en cierto modo, ilusorio. Jünger y Ortega, en este sentido, piensan que el propósito de los sistemas coercitivos de someter a su disciplina todo cuanto existe está abocado al fracaso, debido a las limitaciones que presentan éstos en el ejercicio de su poder. Por ello, una vez descubiertos los mecanismos del poder, el nuevo reto para estos filósofos consiste en hacer visibles los límites del poder nihilista. Esta tarea es vital para orientar al individuo inmerso en las sociedades nihilistas, quien, antes de conducirse hacia la superación de los poderes nihilistas, necesita asegurarse de que tal superación es posible.

Dichos límites se fundan, como veremos a continuación, en la imposibilidad de la educación para racionalizar lo real, por un lado, y en la imposibilidad ontológica de los Estados tecnocráticos para someter a su disciplina la naturaleza del ser humano, por otro. A juicio de estos filósofos, los poderes nihilistas han olvidado que la ley que gobierna la naturaleza interior es inalterable e independiente del control político. Por lo mismo, el imperialismo tecnológico en que se fundan los sistemas capitalistas no puede satisfacer los deseos constitutivos del ser humano, que le impulsan a llevar una vida al margen del consumismo y del bienestar. En suma, lo que no saben los poderosos es que no puede alcanzarse un estado de domino tal por el que la circunstancia llegue a ahogar definitivamente 
el yo singular. Sin embargo, como reitera Jünger, el eros precisa retirarse del mundo de los autómatas.

\section{El fracaso de la educación burguesa ante la irrupción de las fuerzas naturales}

Para Jünger las formas políticas de poder basadas en la educación racional, como las que ejerce el burgués sobre los trabajadores, por su misma esencia, están condenadas al fracaso. En último término dicho fracaso se funda en la imposibilidad de la razón para someter a sus esquemas y principios la naturaleza interior, que actúa según su vocación propia e independiente de la razón. En efecto, la razón solo puede pensar ateniéndose a los principios lógicos y formales, los cuales, sin embargo, no se corresponden con el modo de estructurarse el $\operatorname{ser}^{26}$. Tampoco en el ámbito práctico la ética o la educación pueden domesticar los impulsos humanos que demandan comportamientos alejados de los valores ilustrados de la seguridad y del bienestar: "Las fuentes de lo elemental son de dos especies. Por un lado están en el mundo, el cual es siempre peligroso, como el mar, que siempre encierra dentro de sí el peligro aun en los momentos en los que no sopla el viento. Y por otro lado se hallan en el corazón humano, el cual está siempre anhelando juegos y aventuras, odios y amores, triunfos y caídas, y en todo momento se siente necesitado de peligro y también de seguridad" 27 .

Durante la fase preparatoria de la primera guerra mundial Jünger observa un nuevo fenómeno que pone de manifiesto el fracaso de la Razón en su intento de someter a su dominio el conjunto de la Naturaleza y de la sociedad. La agresión a la Razón Ilega desde órdenes inesperados, incontrolables para el dominio burgués, quien ve cómo sus formaciones sociales, como el individuo o la masa, son reemplazadas por otras de distinta naturaleza. Este fenómeno comienza a hacerse visible en la fase preparatoria de la primera guerra mundial con la aparición de lo que Jünger Ilama "construcciones orgánicas": sistemas funcionales dispuestos

26. Jünger piensa que todo cuanto existe, incluyéndose el conjunto de la Naturaleza, está determinado por lo que él llama la «ley del sello y de la impronta», que nada tiene que ver con el principio racional de causalidad. A juicio del autor, la modernidad, iniciada con el descubrimiento del yo cartesiano y continuada por el giro kantiano de situar al sujeto del conocimiento como centro de reflexión, ha pasado por alto la constatación de las verdaderas leyes que rigen el conjunto de la Naturaleza. Según la concepción metafísica jüngeriana, en cada ser natural actúa una misma fuerza que configura y moviliza el mundo visible, a la que Jünger se refiere con el concepto goethiano de «Gestalt» (Figura). La Figura es, en este sentido, el principio organizador que moviliza la materia de acuerdo a un plan preestablecido, inmanente a ella, y la ley que explica el dominio de una Figura no es la ley de la causa y del efecto, sino la ley del sello y de la impronta, que nada tiene que ver con la causalidad eficiente propia de la concepción moderna mecanicista; véase Jünger, Ernst, El trabajador, "La figura como un todo que abarca más que la suma de sus partes", pp. 38-51.

27. Jünger, Ernst, El trabajador, p. 56. 
para la realización de algún fin que integran elementos técnicos y orgánicos ${ }^{28}$. El fracaso de la razón burguesa en su intento de estructurar la Naturaleza y la sociedad se funda en el hecho de que no es la Razón lo que origina las "construcciones orgánicas", sino la naturaleza impulsiva del ser humano. En efecto, lo que mueve a la formación de este tipo de construcciones, que integran elementos técnicos y humanos, es el impulso de conocimiento del trabajador. A diferencia del burgués, cuya existencia se fundamenta en la creencia de que es posible retirar de sí la naturaleza, el trabajador funda su existencia en la afirmación de los impulsos congénitos de conocimiento y libertad. Quiere acceder a los lugares más insospechados, de ahí que necesite de la técnica para incrementar sus posibilidades de éxito. El trabajador, cuyo estilo de vida se funda en la afirmación de aqueIlo que en vano había tratado de negar el burgués, no concibe la técnica como un medio al servicio del bienestar, sino que se sirve de ella para satisfacer sus impulsos de conocimiento y aventura. La técnica se convierte en el uniforme del trabajador, constituyéndose así la «construcción orgánica» ${ }^{29}$.

El creciente reemplazo de las formaciones burguesas por las "construcciones orgánicas" obedece a que éstas no se desarrollan de un modo aislado, sino conectadas unas a otras, formando nuevas construcciones más amplias. La creciente integración de construcciones orgánicas en unidades más amplias lleva a pensar a Jünger que es el mismo el impulso que late en cada uno de los trabajadores. Lo mismo que Shopenhauer había supuesto la presencia de una voluntad metafísica para explicar la tendencia universal hacia la unión amorosa ${ }^{30}$, Jünger piensa que

28. En su ensayo Fuego y movimiento (1930) Jünger ya se percata de la aparición de las primeras construcciones orgánicas concebidas en la primera guerra mundial para producir movimiento. La nueva guerra de posiciones y el incremento de armas de largo alcance hace que ya no sirvan los movimientos adecuados a las concepciones tradicionales de la guerra. Los tiradores en campo abierto y la movilidad de la artillería ya no valen para afrontar un conflicto que se basa en el aumento del Ilamado efecto de fuego. Para poder avanzar y superar la lucha de posiciones se hace preciso inventar máquinas para producir movimiento. Se trata de los primeros tanques rodantes, cuya influencia en la manera de proceder de la guerra es decisiva debido a su enorme superioridad sobre el individuo y la masa: "La tentativa de romper con medios nuevos unas posiciones fijas, rígidas, probadas en el curso de los tiempos, de romperlas con caballos, corazas, carros de guerra, elefantes, columnas en forma de cuña, es una tentativa que en la edad de la máquina se repite con medios maquinales."; véase Jünger, Ernst, Fuego y movimiento, Barcelona, Tusquets, 1995, p. 139.

29. Un ejemplo de "construcción orgánica» lo tenemos en la fotografía. En la primera guerra mundial la fotografía adquiere el carácter de documento y, desde entonces, no hay acontecimiento significativo que no sea fijado por este "ojo artificial". Este hecho obedece a la pulsión de ver del «tipo» del trabajador, la cual exige que éste se arme con la cámara para alcanzar sus fines: "Se aspira a ver asimismo espacios que se hallan cerrados a los ojos humanos; el ojo artificial atraviesa los bancos de niebla, el vapor atmosférico, las tinieblas, más aún, la resistencia de la propia materia."; véase Jünger, Ernst, Sobre el dolor, Barcelona, Tusquets, p. 71.

30. Véase Shopenhauer, Arthur, Metafísica del amor. Metafísica de la muerte, Barcelona, Obelisco, 1994. 
debe existir un mismo impulso metafísico tras la diversidad fenoménica que explique el orden con el que se organiza el gran proceso. Llama a esta voluntad la «Figura del Trabajador», y a su manifestación fenoménica «trabajo»: "Para poder captar eso es preciso, de todos modos, ser capaz de concebir el trabajo de un modo diferente del rutinario. Es preciso saber que en una «edad del trabajador» nada puede haber que no sea concebido como trabajo (...) Trabajo es el tempo de los puños, de los pensamientos y del corazón; trabajo es la vida de día y de noche; trabajo es la ciencia, el amor, el arte, la fe, el culto, la guerra; trabajo es la vibración del átomo y trabajo es la fuerza que mueve las estrellas y los sistemas solares." (El trabajador, pp. 69-70)

Por tanto, el nuevo impulso metafísico que secunda el trabajador y que late en cada una de las "construcciones orgánicas" se traduce en la creciente aspiración a lo inhóspito y lo peligroso, de la que no quiere saber nada el burgués. Los nuevos fenómenos descritos muestran el fracaso de la pretensión burguesa de someter a los trabajadores mediante la educación. Dicho propósito fracasa en el momento en que se manifiesta la imposibilidad de la razón para frenar la formación creciente de nuevas construcciones, no fundadas en un orden racional. En suma, el dominio en la esfera social del tipo del trabajador sobre el burgués evidencia el triunfo de la realidad impulsiva, no ordenada, sobre la racional.

\section{El fracaso de la nueva disciplina en las sociedades tecnocráticas}

Hemos visto que la Razón fracasa en su intento de domeñar la naturaleza más profunda del ser humano, su realidad inalienable y constitutiva. Tampoco el Estado tecnocrático, que funda su poderío en la reducción del ser a «ser funcional», puede contener las fuerzas no racionales. Recordemos que, a juicio de Jünger y Ortega, el poder de los Estados tecnocráticos radica en su capacidad para someter la libertad singular a la disciplina automática y alejar al ser humano de su ser más propio. Estos autores se convencen, sin embargo, de que la nueva disciplina técnica es incapaz de someter a su legalidad coercitiva el núcleo impulsivo del ser humano, que escapa al control de la razón y de la técnica.

Tras la crisis de los valores trascendentales que siglos atrás orientaban la existencia, para Jünger lo que queda es el «Bosque». Se trata de una metáfora que designa un territorio virgen e inaccesible al Estado tecnocrático desde el que oponer resistencia al poder establecido. El Bosque es el único lugar donde puede la persona singular recluirse y sobreponerse a los imperativos procedentes del automatismo tecnológico. En su ensayo La emboscadura Jünger define al emboscado como aquel que, privado de toda patria y guía espirituales por el gran proceso de despliegue técnico y funcional, mantiene abierto el acceso a su naturaleza interior: "Llamamos Emboscado, en cambio, a quien, privado de patria por el gran proceso y transformado por él en un individuo aislado acaba viéndose entregado al aniquilamiento. Este destino podría ser el destino de muchos y aun el de todos - no es posible dejar de añadir, por tanto, una preci- 
sión. Y ésta consiste en lo siguiente: el emboscado está decidido a ofrecer resistencia y se propone llevar adelante la lucha, una lucha que acaso carezca de perspectivas" ${ }^{\prime \prime}$.

Uno de los referentes que influye en la teoría de la «emboscadura» de Jünger es la obra de Max Stirner El único y su propiedad (1844) ${ }^{32}$. En ella Stirner defiende que las grandes ideologías del pasado no hacen si no alejar al ser humano de su verdadero ser. En efecto, el hombre que en su vida se guía por la búsqueda de algún ideal -como el Bien, la Justicia o la Felicidad-, antepone la voluntad del otro-Dios, el Estado, o la Sociedad- a la suya propia. Es decir, deja de pensar en sí mismo para tratar de cumplir lo que ese ideal espera de él. De esta forma, el hombre pierde el dominio de sí mismo y su existencia le deja de pertenecer. Sin embargo, Stirner considera al ser humano capaz de actuar de acuerdo a otras metas diferentes de las que impone el Estado, la Sociedad o Dios. En el fondo, piensa Stirner, los grandes ídolos de la humanidad han resultado de la escisión del individuo en un yo prescriptivo y un yo obediente. Es el mismo yo el que se desdobla en Otro, dando la impresión de que más allá del yo, existe el Otro como un «ser en sí». En definitiva, los grandes ídolos no son más que fantasmas o meras representaciones humanas que, por sí mismas, carecen del poder efectivo para coaccionar o someter la acción singular. Stirner se convence que desde el momento en que el ser humano cobra consciencia de la dependencia del ídolo respecto de su poder singular, el hombre se hace dueño de éste y recupera su libertad constitutiva: "Se dice de Dios: «Ningún nombre puede nombrarte». Esto vale para mí: ningún concepto me manifiesta, nada de cuanto se indica como mi esencia me satisface: son sólo nombres (...) Propietario de mi poder soy yo mismo, y lo soy en el momento en el cual sé ser único. En el Único el propietario mismo vuelve a entrar en su nada creadora, de la cual ha nacido. Todo ser superior a mí mismo, sea Dios o el hombre, debilita el sentimiento de mi unicidad y empalidece apenas reluce el sol de esta conciencia mía. Si yo fundo mi causa sobre mí, el Único, ella se apoya sobre el efímero, mortal creador de sí que a sí mismo se consume, y yo puedo decir: he fundado mi causa sobre nada" ${ }^{\prime 3}$. Por tanto, el hombre se apropia de su poder en el momento en que sabe de su unicidad y se reconoce como ser «único», y, de esta forma, se da cuenta de que todo ser trascendente (Dios, humanidad, sociedad, Estado...) es una construcción suya. Por el contrario, el «poseído», esto es, el que vive en y para otro, no sabe de su unicidad ni de la dependencia del Otro respecto de su poder, de ahí que éste ya no le pertenezca; lo tiene, pero fuera del alcance de sí mismo.

31. Jünger, Ernst, La emboscadura, Barcelona, Tusquets, 1993, pp. 59-60.

32. Véase Stirner, Max, El único y su propiedad, Madrid, Valdemar, 2004.

33. Stirner, Max, Der Einzige und sein Eigentum, Stuttgart, Reclam, 1972, p. 412 en Volpi, Franco, El nihilismo, p. 38. 
Siguiendo la teoría del poder de Stirner, Jünger piensa que los poderes presentes, ya procedan del Estado totalitario o de las sociedades tecnocráticas, carecen de poder efectivo para impedir hacer o sentir al individuo lo que su fuerza propia le permite hacer o experimentar. Por ello, en última instancia, el poder omnipresente al que aspiran los Estados tecnocráticos es ilusorio, irreal, porque siempre existe un reducto inaccesible e incontrolable para «Leviatán» desde el que resistir. Este reducto es el «Bosque» para Jünger y el «poder singular» para Stirner, los cuales pertenecen a un dominio distinto del control técnico y dependen únicamente de la decisión personal para ser actualizados: "Dos son, pues, las cualidades que en el emboscado se presuponen. En primer lugar, el emboscado no le permite a ningún poder, por muy superior que sea, que le prescriba la ley, ni por la propaganda ni por la violencia. Y, en segundo lugar, el emboscado se propone defenderse; para ello no sólo utiliza los medios y las ideas que son propios de su tiempo, sino que a la vez mantiene abierto el acceso a unos poderes que son superiores a los temporales y que nunca podrán ser diluidos en puro movimiento" ${ }^{\prime \prime 4}$.

También Ortega se refiere al «yo singular»-en oposición al «yo social»como el lugar al que poder recluirse cuando la circunstancia no se conforma con las expectativas y deseos del individuo ${ }^{35}$. Antes hemos visto cómo el mundo tecnológico aleja al ser humano de los espacios reservados para el contacto con su naturaleza interior, favoreciendo la «alteración» y, consecuentemente, el aumento de poder de las sociedades tecnocráticas. Sin embargo, Ortega piensa que existe un anhelo inscrito en lo más hondo del ser humano que exige del «ensimismamiento» para su satisfacción. Se trata del anhelo de autenticidad que nos mueve a ensayar formas diversas de existencia y a intentar descubrir nuestro verdadero ser: "El hombre se inventa un programa de vida, una figura estática de ser que responde satisfactoriamente a las dificultades que la circunstancia le plantea. Ensaya esa figura de vida, intenta realizar ese personaje imaginario que ha resuelto ser. Se embarca ilusionado en ese ensayo y hace a fondo la experiencia de él. Esto quiere decir que llega a creer profundamente que ese personaje es su verdadero ser" ${ }^{\prime \prime 36}$. Dicha aspiración no la puede enfriar ni colmar el mundo tecnológico pese a las infinitas posibilidades que ofrece. En efecto, el mundo tecnológico, si bien puede descubrir y satisfacer infinidad de necesidades, carece de los medios necesarios para evitar que el ser humano quiera realizar su ser, de

34. Jünger, Ernst, La emboscadura, p. 76.

35. El «yo singular» se refiere al ser auténtico, íntimo, es decir, al modo de ser por el cual uno piensa, siente y quiere lo que verdaderamente piensa, siente y quiere. El «yo social», por el contrario, se identifica con el ser impersonal, inauténtico, que corresponde al «se dice», «se piensa», "se quiere»...; véase Ortega y Gasset, Ensimismamiento y alteración, Madrid, Taurus, 2006, Tomo V, pp. 531-550.

36. Ortega y Gasset, José, Historia como sistema, Madrid, Biblioteca Nueva, 2001, p. 92. 
ahí que, por más que lo pretendan, las sociedades tecnocráticas no siempre van a poder conducir la existencia humana hacia fines deseados.

Así, teorías como la «emboscadura» o la «autenticidad» descubren al individuo su posibilidad de vivir de modo distinto a como le impone la circunstancia regida por los imperativos políticos y tecnológicos. Tanto el «emboscado» de Jünger como el «ser auténtico» de Ortega, lo mismo que el «trabajador», fundan su existencia en el impulso de conocimiento y de libertad, que llama al humano a realizar modos de vida que no se ajustan al estilo de vida demandando por las sociedades capitalistas basadas en el bienestar y el consumo. En suma, las figuras del emboscado y del trabajador, lo mismo que el ser auténtico, ponen de manifiesto la imposibilidad de los sistemas coercitivos para enfriar el fondo enérgico del ser humano, al tiempo que muestran al individuo que en su mano está la posibilidad de sobreponerse a los poderes nihilistas.

\section{Conclusiones: el papel de la persona singular en la superación del nihilismo}

Hemos visto que los poderes nihilistas, por su propia esencia, están condenados a fracasar en su intento de ahogar la libertad constitutiva del ser humano. Sin embargo, todavía es preciso dar un paso más para derribar, aunque sea provisionalmente, sus cimientos. El fracaso de las formas nihilistas de poder no conIleva su superación. La consciencia de los límites de los totalitarismos es solo el presupuesto de su derrota, de ahí que todavía sea preciso orientar al individuo en su victoria. Una de las enseñanzas de la teoría de la vocación que desarrollan Jünger y Ortega, como hemos apuntado, consiste precisamente en indicar el lugar desde el que la persona singular puede vencer los poderes presentes. Para estos autores, que han experimentado la crisis anunciada por Nietzsche de los valores e ideales trascendentes, lo que queda es dirigir la atención del ser humano a su fondo interior con el fin de que descubra ahí la fuente donadora de sentido y valor: "En los grandes peligros se buscará lo salvador a mayor profundidad, se lo buscará en las Madres; al contacto con éstas se liberan fuerzas primordiales a las que no pueden hacer frente los puros poderes temporales ${ }^{\prime{ }^{37}}$.

Lo que parecen haber olvidado los poderes presentes es que el nihilismo del que se nutren se supera desde dentro, siguiendo los dictados del corazón y del pensamiento propios, cuyo acceso está reservado a la persona singular. Como una y otra vez reitera Jünger, la lucha para combatir el nihilismo se debe librar en el "propio pecho": "El propio pecho: esto es, como antiguamente en la Tebaida, el centro del mundo de los desiertos y de las ruinas. Aquí está la caverna ante la que se agolpan los demonios. Aquí está cada uno, da igual de qué clase y rango, en lucha inmediata y soberana, y con su victoria se cambia el

37. Jünger, Ernst, La emboscadura, p. 76. 
mundo. Si él es aquí más fuerte, entonces retrocederá en sí la Nada. Dejará en la orilla de playa los tesoros que estaban sumergidos. Ellos compensarán los sacrificios" ${ }^{\prime \prime 38}$. Las figuras del trabajador y del emboscado constituyen, en este sentido, un ejemplo viviente de la superación del nihilismo. En efecto, ambas figuras integran a su proyección vital las posibilidades que ofrece el mundo circundante. No se dejan implicar por la dimensión del poder: se sirven de él y lo explotan si les resulta útil para sus fines personales, de lo contrario, lo ignoran y prescinden de él. En suma, la enseñanza de ambas figuras consiste en mostrar que el cultivo de la libertad comienza por secundar la voluntad de conocimiento y resistencia, y que allí dónde ésta puede darse, aquélla debe proliferar. También Ortega, con su concepción del «ensimismamiento» y de la «vocación», nos enseña que el factor decisivo para contrarrestar los efectos del rumor nihilista consiste en asumir uno mismo la tarea de realizar su vida. En las sociedades tecnocráticas en las que vivimos la ciencia y la tecnología nada nos pueden decir sobre qué hacer y cómo comportarnos ante ellas. Para el hombre libre lo importante no es lo que se pueda hacer con la tecnología sino saber qué hacer con ella. En efecto, de nada sirven las infinitas posibilidades que permite la tecnología o una completa educación sobre lo que ésta nos permite hacer, si no sabemos qué hacer con ella, es decir, si no tenemos claro un proyecto vital en virtud del cual nuestra circunstancia adquiere valor y sentido. Como afirma el filósofo español, la tecnología, por ella misma, no puede realizar la penosa tarea de llenar nuestra vida por nosotros, es mera posibilidad hueca y abstracta: "De puro llena de posibilidades, la técnica es mera forma hueca -como la lógica más formalista-; es incapaz de determinar el contenido de la vida" ${ }^{\prime 39}$.

Por tanto, si bien no podemos cambiar nuestra circunstancia tecnológica, está en nuestra mano cambiar la actitud ante ella. Precisamente, el hombre libre es quien acaba apropiándose de la técnica integrándola en un proyecto. En este sentido, a juicio de Ortega, el verdadero problema que debe afrontar el hombre contemporáneo consiste en el hecho de que, pese a que tiene en su mano la posibilidad de obtener el logro de sus deseos, se encuentra con que no sabe tener deseos: "En su secreto fondo advierte que no desea nada, que por sí mismo es incapaz de orientar su apetito y decidirlo entre las innumerables cosas que el contorno ofrece. Por eso busca un intermediario que le oriente, y lo halla en los deseos predominantes de los demás. He aquí la razón por la cual lo primero que el nuevo rico se compra es un automóvil, una pianola y un fonógrafo. Ha encargado a los demás que deseen por él. Como hay el tópico del pensamiento, el cual consiste en la idea que no es pensada originariamente por el que la piensa, sino tan sólo por él repetida, ciegamente, maqui-

38. Jünger, Ernst, Sobre la línea, p. 69.

39. Ortega y Gasset, Meditación de la técnica, p. 596. 
nalmente reiterada, hay también un deseo tópico, que es más bien la ficción y el mero gesto de desear ${ }^{\prime \prime 4}$.

En el fondo, las filosofías de estos autores son una llamada a la responsabilidad de cada cual a asumir la penosa tarea de realizar nuestro ser en el mundo. La «emboscadura» es una apelación a nuestra naturaleza, lo mismo que el «ensimismamiento» es una llamada al modo de ser propio o auténtico. Por ello, si bien las formas nihilistas de poder fracasan por su propia naturaleza, debido a su imposibilidad constitutiva para anular o controlar los impulsos más propios del ser humano, es necesario apelar a la responsabilidad singular para vencer aquéllas. Esta responsabilidad se funda en el hecho de que el hombre es libre para secundar o contrariar las demandas de su ser. Lo que ha de hacer el ser humano es suspender esa inercia social que le lleva a alejarse de sí mismo y ensayar formas de vida que le hagan recuperar su yo. De su decisión dependerá que se supere o no el nihilismo.

40. Ortega y Gasset, Meditación de la técnica, p. 575. 